\title{
The homeless mentally ill - an audit from an inner city hospital
}

\author{
Aoife O'Neill, Patricia Casey, Rose Minton
}

Ir J Psych Med 2007; 24(2): 62-66

\section{Abstract}

Objectives: To determine the proportion of those that are homeless attending the Mater Misericordiae Hospital's (MUH) psychiatric service, including those presenting to accident and emergency who were homeless, and to compare the homeless group with the non-homeless so as to obtain a profile of this group.

Methods: All adults over 16, referred for psychiatric assessment, attending $A \& E$ were included, as were those attending outpatient clinics, liaison consultations and inpatients in the psychiatric unit, in the six-month period from January to June 2003. Excluded were those who were under 16 , who refused to participate, who did not speak English, those with a diagnosis of personality disorder and organic brain damage. Questionnaires were completed by psychiatric registrars and a community psychiatric nurse, with an ICD-10 diagnosis recorded on each individual, in consultation with the treating consultant psychiatrist.

Results: A total of 628 patients were seen in MUH during the study period, and $13.8 \%$ were homeless. Of the homeless, $56.3 \%$ were seen as emergency referrals in the A\&E, 23\% were inpatients (including the psychiatric unit and consultations in medical/surgical wards) and $20.7 \%$ were seen in the outpatient department. Of all the A\&E referrals to psychiatry, $34.8 \%$ were homeless. The homeless presented most commonly in suicidal crisis (26.6\%) compared with $12.5 \%$ in the non-homeless group. Substance-abuse disorders were the primary diagnosis in $42.3 \%$ of the homeless group, accounting for $14.2 \%$ in the housed sample. Outcome for both groups was similar, with slightly more homeless being referred for psychiatric admission $(17.8 \%)$, as compared to $12.0 \%$ in the nonhomeless group.

Conclusions: Mental illness and the need for psychiatric services remain a serious issue for a significant segment of the homeless population. The homeless are overrepresented in our accident and emergency department, with their psychological and medical needs not being met in primary care. An integrated multi-disciplinary treatment approach, including outreach work, that addresses their many needs, appears to hold the greatest promise of success in this population.

\footnotetext{
*Aoife O’Neill, MB, BMed Sc, MRC Psych, Senior Register, Connolly Hospital, Blanchardstown, Dublin 15, Patricia Casey, FRC Psych, FRCPI, MD, Professor of Psychiatry, Mater Misericordiae Hospital, Rose Minton, Community Psychiatric Nurse, Mater Misericordiae Hospital, 62/63 Eccles St, Dublin 7, Ireland.

*Correspondence

SUBMITTED: APRIL 3, 2006. ACCEPTED: MARCH 30, 2007.
}

Key words: Homelessness; substance abuse; accident and emergency.

\section{Introduction}

Homelessness is a persistent problem in our capital, and a complex one. The sight of people sleeping rough in the doorways of our city stands as a stark reminder that the country's buoyant economy has not benefited all. A comprehensive review of the literature reveals that homelessness and mental illness is a significant problem all over the world. ${ }^{1,2}$

Homelessness is considered the most extreme form of social exclusion, with many of those sleeping rough, living on the streets or in shelters experiencing absolute poverty. This means that they are living without proper shelter, food, or medical care, with little support from family and friends. ${ }^{3.5}$

The nature of the homeless lifestyle means that the homeless are prone to health problems. A number of studies show that homeless people have high levels relative to the rest of the population of mental and physical ill-health; depression, drug and alcohol problems, obesity, hepatitis B and C, and dental problems. ${ }^{6-8} \mathrm{~A}$ recent study has shown that up to $60 \%$ of homeless people had at least one physical or psychiatric problem, with 30\% drinking excessively and 30\% using illegal drugs. ${ }^{9}$ It is thought that about $15 \%$ of the homeless suffer serious effects from social isolation and violence. ${ }^{10}$

Counted In $2005^{11}$ is the third periodic assessment of homelessness in Dublin, carried out in the last week of March 2005 on behalf of the Homeless Agency, with similar assessments done in $1999^{12}$ and $2002 .{ }^{13}$ These assessments have provided a picture of homelessness in Dublin over a sevenyear period. These surveys showed that the number of people sleeping rough increased from 1999-2002, but decreased between 2002 and 2005, with a significant overall decrease of 33\% from 1999-2005.

Counted In 2005 found that the total homeless population reported in Dublin, including adults and children, was 2,015 individuals; 1,552 adults and 463 child dependents. In the 2002 survey, the total homeless population reported was 4,060 individuals; 2,920 adults and 1,140 child dependents. Taking the validation process used in the 2005 survey into account, there was a $19 \%$ reduction in the number of households homeless between 2002 and 2005. These results indicate that some progress has been made in improving the situation in Dublin, and reminds us of the task ahead.

Recent years have seen increased concern about rates of mental illness amongst our homeless population. ${ }^{14}$ Many studies have been carried out and the results suggest that between $30 \%-50 \%$ of the homeless have some form of mental illness. ${ }^{15,16}$ Of particular concern, is the difficulty of accessing this population in order to diagnose illness as well as the problem of engaging them in continuing treatment. ${ }^{17}$ 
There has been much international research in the area of mental health and homelessness to date, but this information is difficult to generalise since the definition of homelessness varies between studies and differing criteria for the diagnosis of mental illness. ${ }^{18}$

Mental illness and the need for psychiatric services remain a serious issue for a significant segment of the homeless population; however, the mental health services already established are underutilised by this population in proportion to their needs. ${ }^{17}$

Population-based studies have shown that homeless persons have high rates of emergency department use; compared with the general population, the homeless are three times more likely to use an emergency department at least once in a year. ${ }^{19}$ This creates a huge strain on already over-burdened emergency departments, with inadequate follow-up in the community, leading to repeated presentations in emergency departments.

The present study was designed to assess the profile of the homeless population presenting to a large inner city hospital.

\section{Objectives}

- To investigate the number of homeless individuals attending the Mater Misericordiae Hospital (MUH) psychiatric outpatients, liaison services and inpatient unit in a given six-month period

- To compare the homeless group with the non-homeless group attending the MUH psychiatric services in that sixmonth period

- To examine the number of homeless individuals with psychiatric presentations who attended the MUH emergency department in a given six-month period.

\section{Method}

\section{Study design}

This study was carried out in the MUH emergency department, psychiatric outpatient clinics, medical/surgical wards and psychiatric inpatient unit in the six-month period from JanJune 2003. The participants consisted of all those seen during this period. Each person in the study had data recorded only once; the results are therefore based on persons not presentations. Verbal consent was required from the participants before questionnaires were completed. Ethical approval was granted by the MUH ethics committee.

\section{Definition of homelessness}

This study used a wide definition of homelessness using a geographical classification, ${ }^{20}$ with the following four categories:

- Street people/those sleeping rough

- Resident of shelters/hostels

- Resident of hotels/bed and breakfasts

- Other unique situations, eg. temporarily staying with family/ friends.

\section{Subjects and raters}

All adults over 16 presenting to the emergency department and referred for psychiatric assessment were included, as were those attending the MUH sector outpatient department, psychiatric consultations by the liaison team, and the inpa- tient unit in that six-month period. Excluded were those who refused to participate, who did not speak the language, those with organic brain damage and diagnoses of personality disorders.

Questionnaires were completed by psychiatric registrars covering the wards and emergency department, while a community psychiatric nurse gathered information from the outpatient clinics and inpatient unit. Psychiatric diagnoses (using ICD-10) were agreed on each patient by a consultant psychiatrist.

A questionnaire with 13 categories of questions was recorded, consisting mainly of 'yes/no' answers and information on demographics, psychiatric history, substance abuse, deliberate self harm, homelessness data, outcome of assessment was obtained and finally an ICD-10 diagnosis was recorded on each individual, the latter being a consensus based on review by the consultant in charge of the patient, and any psychiatric registrar who had also seen the patient, for example, in the emergency department.

\section{Data analysis}

Data was analysed using the Statistical Package for the Social Sciences (SPSS) 11.00.

\section{Results}

A total of 628 patients were seen in $\mathrm{MUH}$ during the study period, of whom $91.9 \%$ were Irish; $47.2 \%$ lived in the Dublin 7 area (the area in which MUH is located), with the next two largest groups living in Dublin 11 area (10.4\%) and Dublin 1 area (10.3\%).

\section{Homeless}

Of the total 628 participants, $13.8 \%$ were homeless, with over half of the homeless group being seen in the accident and emergency department. This homeless group represented $34.8 \%$ of all emergency department referrals to psychiatry. The most common living arrangement was hostel accommodation accounting for $48.2 \%$ (40) of the currently homeless group, while more than one-quarter were roofless.

The length of homelessness ranged from one week to over five years, with $34.8 \%$ recording homelessness for six-12 months.

\section{Homeless and non-homeless compared}

Table 1 and Table 2 give a summary of the results. Over $70 \%$ of the homeless group were referred to outpatients or other services, which included the acute day hospital, psychotherapy services and substance abuse programmes. A similar figure was found in the housed group, with slightly more homeless patients being referred for admission to a psychiatric unit $(17.8 \%$ as compared to $12 \%$ in the nonhomeless group). These results were found to be statistically non-significant.

The results paint a clear picture of the typical profile of the homeless person attending MUH. It is more likely a male patient, under 50 and single, homeless for at least one year, and more likely living in a hostel. He is more likely to present himself to the hospital without GP referral, with a likely history of psychiatric illness and a forensic history, more likely presenting with a suicidal crisis.

$\mathrm{He}$ is more likely diagnosed with a substance abuse 


\begin{tabular}{|c|c|c|c|}
\hline Location of assessment & Homeless \% (n) & Non-homeless \% (n) & Total \\
\hline A\&E & $56.3 \%(49)$ & $16.9 \%(92)$ & $22.5 \%(141)$ \\
\hline Outpatient department & $20.7 \%(18)$ & $68.8 \%(373)$ & $62.2 \%(391)$ \\
\hline Inpatient & $23 \%(19)$ & $14.2 \%(77)$ & $15.3 \%(96)$ \\
\hline Total & $13.8 \%(87)$ & $86.3 \%(542)$ & 628 \\
\hline Demographic profile & Homeless \% (n) & Non-homeless \% (n) & $\mathbf{P}$ \\
\hline Gender & & & $<0.001$ \\
\hline Male & $72.4 \%(63)$ & $46.0 \%(248)$ & \\
\hline Female & $27.6 \%(24)$ & $53.9 \%(291)$ & \\
\hline Total & $100 \%(87)$ & $100 \%(539)$ & \\
\hline Age & & & $<0.01$ \\
\hline$<50$ & $77.0 \%(67)$ & $62.4 \%(334)$ & \\
\hline$>50$ & $23.0 \%(20)$ & $37.6 \%$ (201) & \\
\hline Total & $100 \%(87)$ & $100 \%(535)$ & \\
\hline Mean Age & 39.37 & 43.58 & \\
\hline Marital status & & & $<0.001$ \\
\hline Married/partner & $6.0 \%(5)$ & $26.8 \%(141)$ & \\
\hline Others & $94.0 \%(78)$ & $73.2 \%(386)$ & \\
\hline Total & $100 \%(83)$ & $100 \%(527)$ & \\
\hline Clinical features & Homeless \% (n) & Non-homeless \% (n) & $\mathbf{P}$ \\
\hline Referral source & & & $<0.001$ \\
\hline Self & $50.0 \%(43)$ & $14.4 \%(73)$ & \\
\hline GP & $8.1 \%(7)$ & $40.6 \%(206)$ & \\
\hline Other & $41.9 \%(36)$ & $45.0 \%$ (228) & \\
\hline Total & $100 \%(86)$ & $100 \%(507)$ & \\
\hline Current presentation & & & $<0.001$ \\
\hline Affective and anxiety symptoms & $25 \%(16)$ & $52.7 \%(185)$ & \\
\hline Psychotic symptoms & $7.8 \%(5)$ & $10.5 \%(37)$ & \\
\hline Suicidal crisis & $26.6 \%(17)$ & $12.5 \%(44)$ & \\
\hline Substance abuse difficulties & $21.9 \%(14)$ & $15.9 \%(56)$ & \\
\hline Other & $18.7 \%(12)$ & $8.3 \%(29)$ & \\
\hline Total & $100 \%(64)$ & $100 \%(351)$ & \\
\hline Medications & & & $<0.05$ \\
\hline Antidepressant meds & $29.7 \%(11)$ & $53.9 \%(206)$ & \\
\hline Antipsychotic meds & $35.1 \%(13)$ & $20.2 \%(77)$ & \\
\hline Anxiolytics & $5.4 \%(2)$ & $7.1 \%(27)$ & \\
\hline Antidepressants/antipsychotics & $29.7 \%(11)$ & $18.8 \%(72)$ & \\
\hline Total & $100 \%(37)$ & $100 \%(382)$ & \\
\hline Forensic history & & & $<0.001$ \\
\hline Charged in court & $51.7 \%(15)$ & $42.4 \%(14)$ & \\
\hline Imprisonment & $27.5 \%(8)$ & $24.2 \%(8)$ & \\
\hline Hx of violence & $10.3 \%(3)$ & $21.2 \%(7)$ & \\
\hline Other & $10.3 \%(3)$ & $12.1 \%(4)$ & \\
\hline Total & $100 \%(29)$ & $100 \%(33)$ & \\
\hline ICD-10 diagnoses & & & $<0.001$ \\
\hline Affective disorders & $11.8 \%(10)$ & $31.9 \%$ (168) & \\
\hline Neurotic and stress disorders & $8.2 \%(7)$ & $14.6 \%(77)$ & \\
\hline Schizophrenia & $17.6 \%(15)$ & $15.4 \%(81)$ & \\
\hline Substance abuse & $42.3 \%(36)$ & $14.2 \%(75)$ & \\
\hline${ }^{*}$ Co-morbid disorder & $16.5 \%(14)$ & $22.2 \%(117)$ & \\
\hline Other & $3.5 \%(3)$ & $1.5 \%(8)$ & \\
\hline Total & $100 \%(85)$ & $100 \%(526)$ & \\
\hline
\end{tabular}


related problem than a non-homeless patient. He is more likely a 'walk-in' patient to the accident and emergency department or a medical inpatient and less likely to be attending the psychiatric outpatient clinic than the non-homeless patient.

From the accident and emergency data in Table 2 it is interesting to note that almost $90 \%$ of the homeless group were self-referrals, with only $4 \%$ having a GP referral, but a high percentage were self referrals in the non-homeless group also (72.5\%). In both groups, the majority were referred for admission in MUH and then psychiatric hospitals locally.

\section{Discussion}

The high prevalence of mental disorders in our study is in line with the results of many other studies in the field. ${ }^{2,21}$ However, direct comparisons between studies on psychiatric prevalence among homeless populations are difficult to make because of differing sampling methods, healthcare systems and numerous other factors that affect the composition of study groups or the occurrence of mental illness among them. ${ }^{18}$

Our study has focused specifically on the homeless and the mental illnesses they present with in an inner city general hospital in Ireland, and in this regard it is unique.

Epidemiological studies indicate a strong relationship between homelessness and substance abuse disorders. Approximately one third to one half of the homeless manifest current psychiatric disorders, with dramatically high rates of alcohol-use disorders; as high as $64 \%$ in some samples ${ }^{22}$ which is often co-morbid with another mental illness. ${ }^{23,24}$

In our study, substance abuse disorders (included alcohol and drug abuse) were the primary diagnosis in $42.3 \%$ of the homeless surveyed - this diagnosis accounted for only $14.2 \%$ of the non-homeless group. Substance abuse-related difficulties was a presenting complaint in $21.9 \%$. It is interesting to note that the commonest presentation and reason for psychiatric referral in the homeless $(26.6 \%)$ was a suicidal crisis - however a large number of this group would have been diagnosed with a substance abuse disorder, highlighting the role that alcohol and drug abuse have in being the single biggest factor in these individuals presenting to our emergency departments.

Rates of co-morbid psychiatric illness and substance abuse have been found to range from 4\%-26\%, with a working assumption that approximately $10 \%-20 \%$ of the homeless population fulfil the criteria for a dual-diagnosis. ${ }^{23}$ In our study, a co-morbid diagnosis was found in $16.5 \%$ of the homeless group, in keeping with the above figures.

We would expect a higher prevalence of co-morbidity in the homeless population when compared to the non-homeless, but in this study this was not the case $(22.2 \%$ in the non-homeless).

This raises the possibility that other psychiatric diagnoses were overlooked/not evaluated in the homeless group with substance abuse difficulties. Alternatively, it may be that the general population served by the MUH has a higher than expected rate of co-morbidity, being an inner city area.

Regarding diagnoses of specific mental illness, studies have been consistent in their estimates of prevalence; $10 \%$ $13 \%$ schizophrenia, 21\%-29\% with affective disorders, $10 \%-20 \%$ with a co-morbid diagnosis and $2 \%-3 \%$ with
Table 2: Accident and emergency homeless and non-homeless assessments

Homeless \% (n) Non-homeless \% (n)

$\begin{array}{lcc}\text { Referrals } & & \\ \text { Self } & 87.5 \%(43) & 72.5 \%(66) \\ \text { GP } & 4.0 \%(2) & 10.9 \%(10) \\ \text { Other } & 8.1 \%(4) & 16.4 \%(15) \\ \text { Total } & 100 \%(49) & 100 \%(91)\end{array}$

Outcome

OPD referral/other $\quad 62.7 \%(27) \quad 54.5 \%(48)$

Inpatient referral $\quad 25.5 \%(11) \quad 23.8 \%(21)$

Discharged $\quad 11.6 \%(5) \quad 21.5 \%(19)$

Total $\quad 100 \%(43) \quad 100 \%(88)$

Inpatient referrals

MUH Psych Unit

St Vincent's Fairview

St Brendan's

Other

$36.3 \%(4)$

$57.1 \%(12)$

$9.0 \%(1) \quad 9.5 \%(2)$

$27.2 \%(3) \quad 33.3 \%(7)$

$27.2 \%(3) \quad 0 \%(0)$

Total $\quad 100 \%(11) \quad 100 \%(21)$

dementia. ${ }^{23}$ Our study reflected these figures with $17.6 \%$ having a diagnosis of schizophrenia, the second most common diagnosis after substance abuse. However, our figures for affective disorder were much lower.

Much has been written about the over-representation of homeless persons among users of emergency departments. The features of and services offered by emergency departments $(24 \mathrm{hr}$ accessibility, treatment of acute injuries, no appointment required, etc.) encourage this use. Emergency departments are limited in their ability to provide adequate services for the range of mental health problems they are presented with. ${ }^{17}$

In this study, $34.8 \%$ of the psychiatric referrals in A\&E were homeless. This represents a large burden on an already overburdened emergency department and under-resourced psychiatric service. The nature of homelessness and being 'rootless' means that the homeless tend to present in any number of emergency departments attached to different hospitals, with little continuity of care as a result. When referred to specialised psychiatric and substance abuse services, drop-out rates are high. ${ }^{22,25}$ This is particularly true for those homeless with more severe psychopathology and whose needs are great. ${ }^{26}$

It is encouraging to see from our results that up to $90 \%$ of the homeless that presented for psychiatric assessment had follow-up arranged within the psychiatric services. The outcome figures in the non-homeless were similar with fewer admitted to hospital.

We have no information on whether these follow-up arrangements were adhered to, a result that would demonstrate the adequacy or otherwise of services for the homeless with mental illness.

There are limitations to our study, in that the population studied would not be representative of the general population, as MUH serves an inner city population, with much social deprivation. Psychiatric registrars were involved in making the diagnosis, which was often made after one assessment, raising the possibility of these being unreliable. 
However, for those attending the outpatient clinic, diagnosis was confirmed in consultation with the treating consultant.

\section{Implications}

There is a lack of specialised services for homeless individuals in Dublin to address both their physical and mental health as well as their substantial substance abuse problems. Developing a patient profile thus helps us to focus our attention on areas where treatment and services can be improved and made more accessible to the patient.

The needs of the homeless population are multi-dimensional and need to be responded to in a holistic way. Current services for the homeless tend to be narrowly focused; on meeting the immediate needs of homeless people for food and shelter. There has been little emphasis on linking people to appropriate services, reintegrating them into mainstream housing or preventing them from becoming homeless in the first place.

As a first step it seems crucial that the mental health services dedicate special teams of mental health professionals and general practitioners whose work is solely with the homeless. This has already been started in recent years with outreach work and case management strategies, introducing greater flexibility in mental health services to care for the mentally ill homeless. An integrated multi-disciplinary treatment approach that addresses psychiatric, substance abuse and physical problems and assists individuals in meeting basic needs, including accessing primary care, appears to hold the greatest promise of success in this struggling population. It is important that co-ordination between community and voluntary organisations working within the homeless sector is strengthened as service provision for the homeless relies strongly on this sector. ${ }^{27}$ We hope that the findings of this study highlight the many mental health issues in our homeless population and assist in the planning of community mental health services in Dublin's inner city.

\section{Acknowledgements}

We would like to thank Margaret Walsh for statistical assistance in preparation of this paper.
Declaration of Interest: Funded by the Northern Area Health Board.

References;

1. Fisher PJ, Breakey WR. The epidemiology of alcohol, drug and mental disorders amongst homeless persons. Am Psychologist 1991; 46(11): 1115-1128.

2. Koegal P, Burnam MA, Farr RJ. Alcoholism among homeless adults in the inner city of Los Angeles. Arch Gen Psych 1988; 45(11): 1011-1018.

3. Combat Poverty Agency. Factsheet: Homelessness and Poverty. Dublin. Combat Poverty Agency, 2004.

4. Corr C. 'A Step in the Right Direction: An Evaluation of the Failtiu Information and Advice Service' In: 'Pieces of the Jigsaw: Six Reports addressing Homelessness and Drug Use in Ireland'. Dublin. Merchants Quay Ireland. 2003a.

5. Homeless Agency. Shaping the Future: An Action Plan on Homelessness in Dublin. Dublin: Homeless Agency, 2001.

6. Condon M. The Health and Dental Needs of Homeless People in Dublin. Dublin: Northern Area Health Board; 2001.

7. Holohan T. Health Status, Health Service Utilisation and Barriers to Health Service Utilisation among the Adult Homeless Population of Dublin. Dublin: Eastern Health Board; 1997

8. Feeney A, McGee H, Holohan T, Shannon W. Health of Hostel Dwelling Men in Dublin. Dublin: Royal College of Surgeons in Ireland and Eastern Health Board; 2000. 9. Holohan T, Holohan W. Health and Homelessness in Dublin. Ir Med J 2003; 93(2): 41-3. 10. Mc Keown K. Mentally III and Homeless in Ireland: Facing the Reality, Finding the Solutions. Disability Federation of Ireland; 1999.

11. Counted In 2005. Homeless Agency, Dublin; 2005.

12. Williams J, O'Connor M. Counted In: The Report of the Assessment of Homelessness in Dublin. Dublin: Homeless Agency; 1999.

13. Williams J, Gorby S. Counted In 2002: The Report of the Assessment of Homelessness in Dublin. Dublin: Homeless Agency; 2002.

14. Amnesty International. Mental IIIness: The Neglected Quarter-Homelessness. Amnesty International, All Ireland Section; 2003.

15. Hitchcox M, Maurin JT, Russell L. Obstacles to research analysis. J Psychosoc Nursing 1989; 27: 9-13

16. Allen D. Mental illness for up to 50 per cent of homeless people. Nursing Standard 16. Allen D. Ment 24 : 8 .

1993; 24: 8. J Acc Emer Med 1996; 13: 415-517.

18. Munoz M, Vazquez C, Koegal P, Burnam MA. Differential patterns of mental disorders among the homeless in Madrid (Spain) and Los Angeles (USA). Soc Psychiatry Epidemiol ; 1998; 33: 514-520.

19 . Kushel et al. Factors associated with the health care utilization of homeless persons. JAMA 2001.

20. Roth D, Bean GJ. New Perspectives on homelessness: findings from a statewide epidemiological study. Hosp Comm Psychiat 1986 .

21. Marshall EJ, Reed JL. Psychiatric morbidity in homeless women. Br J Psychiatry 1992; 160: 761-768.

22. Mavis BE, Humphreys K, Stoeffelmayr BE. Treatment needs and outcomes of two subtypes of homeless persons who abuse substances. Hosp Comm Psychiatry 1993; 44(12): $1185-1187$.

23. Drake RE, Osher FC, Wallach MA. Homelessness and dual diagnosis. Am Psychologist 1991; 46: 1149-1158.

24. Tessler RC, Dennis DL. A synthesis of NIMH-funded research concerning persons who are homeless and mentally ill. Rockville, MD: Program for the HMI, Division of Education and Service Systems Liaison, NIMH 1989.

25. Stahler GJ, Stimmel B.The effectiveness of social interventions for homeless substance abusers. New York: Hawthorn Press, Inc. 1995.

26. Mierlak D, Galanter M, Spivack N, Dermatis H, Jurewicz E, De Leon G. Modified therapeutic community treatment for homeless dually diagnosed men: who completes treatment? J Sub Abuse Treatment 1998; 15(2): 117-121.

27. O'Sullivan E. The State, Voluntary Agencies, Housing and Homeless Services in the Republic of Ireland. Dublin. University of Dublin, Trinity College. 1998. 